\title{
Risk factors analyses and preventive measures of immersed tunnel engineering
}

\author{
Jiao Zhang*, Sainan Fu, Jianping Zhu, Jiancheng Wang \\ School of Civil and Transportation Engineering, Shanghai Urban Construction Vocational College, Shanghai 200432, China
}

\begin{abstract}
Based on the comprehensive analyses of many risk factors leading to accidents in immersed tunnel engineering, it is concluded that the risk factors leading to accidents in immersed tunnel engineering are very large and must be paid attention to in all aspects at all stages of the project. This paper classifies and identifies the risk factors in immersed tunnel engineering by investigating and visiting the relevant investigation, design and construction units of immersed tunnel, and then puts forward prevention and control measures to provide theoretical basis for the prevention of risk factors in Immersed Tunnel Engineering in the future and the risk management of the whole project.
\end{abstract}

\section{Introduction}

The world's first railroad immersed tunnel was completed in 1901 in the United States. Since Hong Kong built China's first cross-port immersed tunnel in 1972, it has been applied more and more to our country's cross-river and sea-crossing projects. With the advantages of not being affected by weather and not affecting navigation, as well as crossing large-span straits, the immersed tunnel method is more and more widely adopted by Chinese tunnel builders. The completion of the $5.6 \mathrm{~km}$ immersed tunnel, Hong Kong-Zhuhai-Macao Link Project, marks a relatively weak country in immersed tube tunnel technology developing into one of the leading countries in the international tunnel industry [1-3].

However, the immersed tunnel engineering has many potential risks. Since the process of immersed tunnel engineering is complicated and difficult, it is easily affected by factors such as severe weather, tides, water flow speed, and river water level and the base slot excavation, segment floating, sinking and docking stages will also affect the river channel transportation, huge personnel and property losses will be caused if a large engineering accident occurs. At this stage, how to analyze and prevent the risk factors of immersed tunnel engineering is an important research direction in tunnel construction, and it is also an important topic that both project owners and contractors must face. More and more experts and scholars are concerned about how to prevent and reduce the occurrence of risk accidents in immersed tunnel projects. Through a large number of investigations by the construction parties, the paper identifies and analyses risks in immersed tunnel projects and propose corresponding risk control measures.

\section{Visit and Research Plan}

\subsection{Research purpose}

By visiting and researching the construction parties of various tunnel projects and experts, studying the potential, appearance and development trend of various risk factors, identifying and analyzing the types of risk factors in immersed tunnel engineering, corresponding risk management measures are proposed, which provides theoretical and practical basis for similar tunnel construction.

\subsection{Methods and objects of Research}

Adopting network research methods such as visit and research method, expert interview method, Sojump questionnaire, a survey form on risk factors of immersed tunnel engineering and an outline of expert interviews are compiled. 163 total questionnaires and 157 valid questionnaires are received after visiting and researching companies including CCCC Fourth Aviation Institute, CCCC Third Aviation Administration, CCCC Fourth Shipping Bureau, related construction units of Shanghai Construction Engineering (eight subsidiaries), overseas business departments of related companies, Shanghai Jianke Construction Supervision Consulting Co. , Ltd., Shanghai Municipal Design Institute, Shanghai Basic Engineering Group Co., Ltd., Shanghai Urban Construction Design and Research Institute.

\subsection{Contents of the research}

The main research contents include:

"Corresponding author's e-mail: ggglg@163.com 
(1) The name of your organization and the project name of the immersed tunnel engineering undertaken;

(2) Which aspect of your organization is mainly engaged in?

(3) How many projects has your organization undertaken?

(4) What do you think are the shortcomings of the immersed tunnel engineering in our country?

(5) What risk factors do you think exist in the immersed tunnel engineering?

(6) What suggestions do you think about the training of professionals for immersed tunnel engineering?

(7) What improvements do you think about the immersed tunnel engineering?

(8) What aspects of risk factor management do you think exist in immersed tunnel engineering?

(9) What do you think is the future development direction of immersed tunnel technology?

The main contents of the interview outline with experts from the participating parties:

(1) With the development of enterprises and industries driven by the One Belt One Road policy, what is the development prospect of immersed tunnels in order to adapt to the adjustment of industrial structure?

(2) What abilities do you think should be possessed by relevant talents engaged in the design and construction of immersed tunnel engineering? Please explain from the aspects of professional technical ability, adaptability, business ability, management ability, innovation ability, etc.;

(3) In your opinion, what are the controllable and uncontrollable risk factors in immersed tunnel construction engineering?

(4) What risk management measures do you think are the risk factors in the immersed tunnel engineering?

(5) What are your views and suggestions on the development prospects of immersed tunnel engineering?

\section{Research steps for immersed tunnel engineering}

Immersed tunnel engineering is characterized by frequent occurrence of disastrous weather, complicated technology, and the use of new technologies, new techniques, and new equipment. Survey questionnaires and expert interview records need to be sorted out and various risk factors of immersed tunnel engineering need to be classified and evaluated [4]. Due to the fact that risk analyses and evaluation, facility design, construction and management requirements are integrated and risk factors change with time, it is necessary to propose preventive measures corresponding to the risk assessment methods and standards of immersed tunnel engineering in order to completely control the risk factors of immersed tunnels. The construction investigation steps of the immersed tunnel engineering are shown in Figure 1.

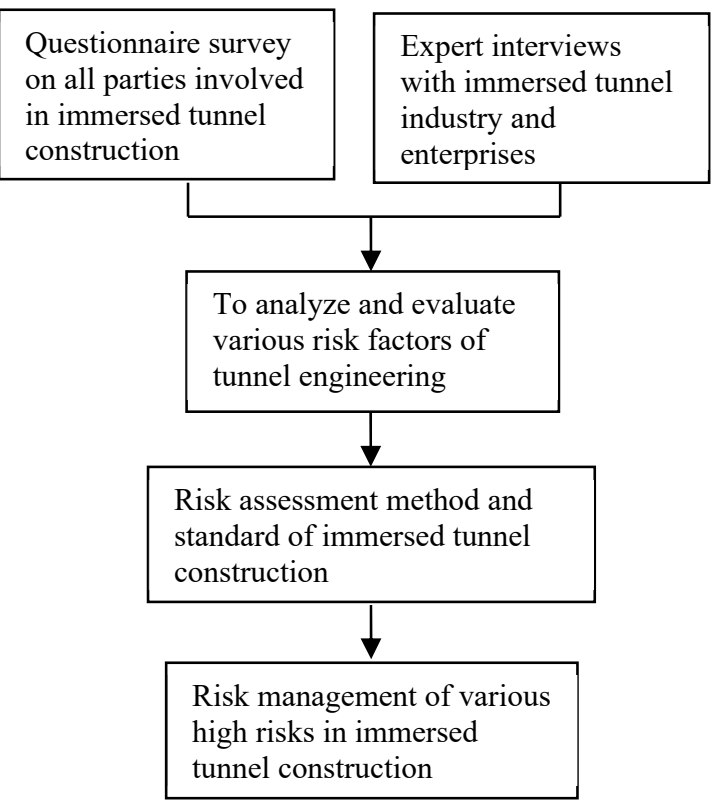

Fig 1. Research steps of immersed tunnel engineering.

\section{Analyses of risk factors of immersed tunnel engineering}

The various risk factors of immersed tunnel engineering are analyzed as shown in Table 1.

Table1. Risk factors of immersed tunnel engineering.

\begin{tabular}{|l|l|}
\hline Construction phase & Potential risk factors \\
\hline (1) Bank-protection work & 1) Large deviation of foundation soil \\
\cline { 2 - 2 } & 2) River water level, bad weather \\
\hline \multirow{2}{*}{ (2) Dry dock construction } & $\begin{array}{l}\text { 1) Failure of structure and precipitation system, resulting in flooding of } \\
\text { dry dock }\end{array}$ \\
\cline { 2 - 2 } & 2) Insufficient water depth design \\
\cline { 2 - 2 } & 3) Insufficient bearing capacity of the dock bottom \\
\hline (3) Fabrication of immersed pipe section & 1) Negative deviation of pipe section material \\
\cline { 2 - 2 } & 2) Water leakage in the tunnel (poor water tightness) \\
\cline { 2 - 2 } & 3) Poor symmetry and uniformity of pipe sections \\
\cline { 2 - 2 } & 4) Poor anti-floating safety factor \\
\hline
\end{tabular}




\begin{tabular}{|c|c|}
\hline & 5) Failure of the ballast tank \\
\hline \multirow[t]{4}{*}{ (4) Tunnel dredging } & $\begin{array}{l}\text { 1) Exposed base trench of the pipe section for a long time, too much back } \\
\text { siltation }\end{array}$ \\
\hline & $\begin{array}{l}\text { 2) Insufficient base leveling accuracy, improper base elevation, pipe } \\
\text { section removal }\end{array}$ \\
\hline & 3) Slope collapse of foundation trench \\
\hline & 4) Improper selection of dredging machinery \\
\hline \multirow{7}{*}{$\begin{array}{l}\text { (5) Floating transportation of immersed } \\
\text { pipe section }\end{array}$} & 1) Improper selection of special device for floating of pipe section \\
\hline & 2) Failure of tugboat \\
\hline & 3) Collision of the undock entrance \\
\hline & $\begin{array}{l}\text { 4) Insufficient estimation of hydrological and meteorological data (tidal } \\
\text { water) }\end{array}$ \\
\hline & 5) Unreasonable selection of the formation method of tube tugboat floats \\
\hline & 6) Stranded pipe section, stranded tugboat \\
\hline & 7) Damage to the pipe partition and GINA waterstop \\
\hline \multirow{5}{*}{$\begin{array}{l}\text { (6) Immersion placement of immersed } \\
\text { pipe section }\end{array}$} & 1) Improper selection of placement method \\
\hline & 2) Misaligned with the center line of the tunnel \\
\hline & 3) Collision by other ships \\
\hline & 4) Failure of end seal door and other seal \\
\hline & 5) Insufficient anti-floating ability of tunnel pipe section \\
\hline \multirow[t]{4}{*}{ (7) Connection of immersed pipe section } & 1) Leakage of pipe section joints \\
\hline & 2) Improper selection of pipe connection method \\
\hline & 3) The joint dislocation caused by uneven settlement of the pipe section \\
\hline & 4) Waterproof failure when the GINA waterstop is in contact \\
\hline \multirow[t]{3}{*}{ (8) Final joint } & 1) Failure of final joint steel plate \\
\hline & 2) Failure of the hydraulic system \\
\hline & 3) Failure of water stop system \\
\hline \multirow[t]{5}{*}{ (9) Foundation treatment and backfilling } & 1) Failure or improper use of construction equipment \\
\hline & 2) No real-time monitoring \\
\hline & 3) Improper selection of basic treatment methods \\
\hline & $\begin{array}{l}\text { 4) Unbalanced substrate treatment, the sides and top of the pipe section } \\
\text { not covered with soil }\end{array}$ \\
\hline & 5) Failure or improper operation of ship equipment \\
\hline \multirow{4}{*}{$\begin{array}{l}\text { (10) Subsidiary construction work in the } \\
\text { sea }\end{array}$} & 1) Improper diving protection \\
\hline & 2) Lack of necessary protective measures or missteps \\
\hline & 3) Bad weather \\
\hline & 4) Failure or improper use of construction equipment \\
\hline
\end{tabular}

\section{Construction risk management measures for immersed tunnel engineering}

In view of the various potential risks in the immersed tunnel engineering, various risk management measures should be put forward in time [5-7] to avoid the huge economic and personnel losses caused by possible accidents [8,9]. The management measures for such risk factors are as follows:

\subsection{Risk management measures for bank protection works}

After checking the current hydrogeological data, the bank protection slope needs to be reinforced based on the geological research data. The key lies in paying attention to drainage requirements, keeping the wall flat, and stopping water treatment at the joints of each bank protection section. 


\subsection{Risk management measures for dry dock construction}

During the dry-dock construction, the stability and safety of the dry-dock's slope are monitored, and early prevention is aimed at risk factors. After the dry dock construction is completed, a water immersion test shall be carried out. If it fails to pass, the slope shall be reinforced, and even the mortar surface method shall be used to prevent water seepage.

\subsection{Risk management measures for the production of immersed pipe sections}

Effectively control the quality of concrete raw materials and strictly control temperature cracks; strictly control the production, pouring, vibrating and curing of immersed concrete; strengthen the control of bulk density and geometric dimensions of segment prefabrication, and ensure the freeboard and anti-floating safety factor; reasonably choose the waterproof material of the immersed pipe section to ensure the waterproof performance of the pipe section so that no leakage accident occurs after the tunnel is put into use.

\subsection{Risk management measures for tunnel dredging}

Reasonably select dredging machinery; the plane axis of the excavation of the foundation trench should be consistent with the plane axis of the immersed pipe section; strictly control the elevation of the bottom of the foundation trench; the dredging operation should be carried out in layers and sections to determine the stability of the underwater foundation trench slope and reasonable slope rate, to ensure that the slope of the foundation trench is not unstable, and to ensure the leveling accuracy of the foundation during precise excavation;

\subsection{Floating risk management measures for immersed pipe sections}

Measure the width of the river bed or seabed, tide water, flow velocity, river or sea water gravity, wind speed, shipping conditions, wave height, weather conditions, etc. to determine the special device for pipe section floating, which aims at the tunnel center line to sink; reduce ship noise, prevent ships collision and reasonably select the tube section tug boat floating ship formation method (towed by tugboat or shore winch) to prevent the pipe section from stranding; make sure the pipe section cannot be swayed during floating to prevent ship equipment failure or improper operation;

\subsection{Risk management measures for immersed pipe sections}

Before sinking, check the sinking equipment, adjust the pitch attitude of the pipe section to reduce the shaking of the steel pontoon due to the influence of waves; all persons in the pipe must leave before the sinking of the pipe section begins and they can enter the pipe again for hydraulic crimping after pulling the pipe section and initially stopping the water; it is necessary to dive for multiple times to examine and conduct preliminary docking of the pipe section in the stage of the pipe section approaching and landing.

\subsection{Risk management measures for the connection of immersed pipe sections}

The connection of the immersed pipe section mainly adopts the hydraulic crimping method to ensure that the joints of the pipe section do not leak; ensure the material of the hydraulic crimping joint; after the crimping is completed, remove the two end sealing walls that have just been butted.

\subsection{Risk management measures of final joint}

The final joint of the immersed tube tunnel is one of the key procedures of the entire project, which has the characteristics of heavy weight and high construction risk [10]. The final joint contacts the adjacent pipe section and compresses the temporary waterstop to form a sealed joint cavity; for structural waterstop, after the water body of the joint well is drained, the blocking walls of the pipe section and the buried section can be opened. If leakage occurs, measures must be taken to plug and drain in time.

\subsection{Foundation trench and basic risk management measures}

After detailed geological surveys, appropriate foundation trench excavation methods and excavation machinery are selected to ensure the accuracy and efficiency of the underwater trench excavation. The correct foundation treatment methods are used according to the actual project to ensure the balance and integrity of the foundation, reduce foundation settlement and conduct real-time monitoring. Combined with experiments and precision instrument measurements, it provides a basis for the design of the foundation trench and ensures the accuracy of the design of the foundation trench.

\subsection{Risk management measures for subsidiary construction operations in the sea}

Strengthen personal protection and construction operation guidance, carry out regular safety inspections, strengthen construction safety management, take post-protection operations, pay attention to weather forecasts, and stop operations in bad weather.

\section{Conclusions}

In view of the analyses of various risk factors in the immersed tunnel engineering, after visiting and investigating the participating construction parties of the immersed tunnel engineering, the comprehensive analyses 
of various risk factors of immersed tunnel engineering that may cause accidents analyses is carried out.

Management measures for various risk factors of immersed tunnel engineering are put forward to reduce risks, which provide a theoretical basis for the accident prediction of immersed tunnel engineering, among which construction procedures including the floating, settlement of pipe sections, and the excavation of foundation trenches is relatively risky, requiring corresponding risk measures to be adopted to ensure the safety of project construction.

Immersed tunnel engineering is a long-term construction project, and its risk management is a dynamic process. As the project progresses, the construction environment and characteristics will change, and new construction risks will emerge. The probability of occurrence of risk factors in different processes is also different. To fully control the risk factors during the construction period, it is necessary to control each process. Risk management must be carried through the entire installation construction process of immersed tube floating and covering all operating procedures. The key to follow-up research lies in effective dynamic risk management of immersed tunnel engineering.

\section{Acknowledgments}

This work was supported by the School-level Scientific Research Project of Shanghai Urban Construction Vocational College (No. cjky202109).

\section{References}

1. Huang, Z., Zhang, H., Zhang, C.L., Fu, H.L., Ou, Z.Y. (2020) Comprehensive risk assessment model and its application in early stage construction for immersed tunnel. Catastrophe Science, 35(2): 55-61.

2. Zhang, J., Liao B. (2019) Risk analysis and control for immersed tunnel construction. Railway Construction, 59(2): 98-101

3. Zhang Z.G., Li J.F. (2019) Application and demonstration of Health-Safety-Environment risk management to underwater tunnel of Hong KongZhuhai-Macao Link. Tunnel Construction (Chinese and English). 39(2): 189-196.

4. Jiang, W., Yuan, Y. (2020) Effects of cracking parameters on immersed tunnel during precasting. China Journal of Highway and Transport, 33(2): 114124.

5. Cheng, Y., Zhu, H.H., Liu, S.Y., Liu, X.Z. (2016) Risk assessment for construction of large-span and shallow buried highway tunnels based on fuzzy theory. Chinese Journal of Underground Space and Engineering, 12(6): 1616-1622.

6. Hong Kong-Zhuhai-Macao Link Project Authority (2013) Tunnel Engineering Construction and Quality Acceptance Standards for the Main Works of Hong Kong-Zhuhai-Macao Link Project.

7. China Communications Highway Planning and Design Institute Co., Ltd. (2011) Construction
Drawing Design of Island Tunnel Project of the Hong Kong-Zhuhai-Macao Link Project.

8. Shang, Q.K., Fu, X.P., Zhu, L., Hou, Y.F. (2018) Construction Risk Management System of the Immersed Tunnel of Hong Kong-Zhuhai-Macao Link Project. Highway. 63(8): 31-36.

9. Zhang, D.M., Bai, Y.J., Bai, X., Wang, Z., Zhao X.P. (2018) Evaluation and prediction of the geological hazards in the deep-buried long tunnel project through fuzzy-hierarchical analysis. Journal of Safety and Environment, 18(1): 50-55.

10. Chen, L., He, B., Yang, X. (2018) Desilting technology of offshore immersed tube tunnel at final joint, China Harbor Construction, 38(7): 16-20. 